\title{
EDUCAR LA MIRADA. EL DISCURSO INFORMATIVO DE LAS FAKE NEWS EN EL CURRÍCULO DE SECUNDARIA Y BACHILLERATO
}

\author{
Francisco José Sánchez García \\ Universidad de Granada
}

\begin{abstract}
RESUMEN: En los últimos años, asistimos a la profunda transformación de los hábitos de consumo informativo de las nuevas generaciones, que avanza en paralelo al desarrollo de las redes sociales y de mensajería - WhatsApp, Facebook, Twitter- La sobreabundancia de noticias y la facilidad de acceso a estos contenidos, que a priori tendríamos que entender como una gran ventaja, presenta un problema crucial, que tiene que ver con la alarmante falta de criterio de los adolescentes sobre la veracidad o falsedad de estas noticias que circulan por la red, y que en muchos casos sirven a intereses manipuladores. Por ello, en este artículo repasaremos las principales aportaciones sobre la difusión viral y consumo de fake news por parte de los jóvenes españoles, así como el papel que los contenidos de prensa y medios de comunicación desempeñan actualmente en la enseñanza no universitaria, insistiendo en la necesidad de acometer el problema desde la raíz, esto es, abordándolo como un elemento básico del currículo de Lengua castellana y literatura en Educación Secundaria Obligatoria y Bachillerato.
\end{abstract}

PALABRAS CLAVE: fake news, posverdad, innovación educativa, discurso informativo, redes sociales.

\section{EDUCATING THE OUTLOOK. THE INFORMATIVE DISCOURSE OF FAKE NEWS IN SECONDARY AND BACHILLERATO CURRICULUM}

\footnotetext{
ABSTRACT: In recent years, we have witnessed the profound transformation of information consumption habits in the new generations, in parallel progress with the development of social and instant messaging networks - WhatsApp, Facebook, Twitter-. The overabundance of news and easy access to this content, which a priori would have to be regarded as a great advantage, presents a crucial problem, which has to do with the alarming lack criteria that adolescents have about the truth or falsity of the kids of news that circulate on the web, and that in many cases serve manipulative interests. For this reason, in
} 
this article we will review the main contributions on the viral dissemination and consumption of fake news by young Spanish people, as well as the role that the press and media content creators currently play in non-university education, insisting on the need to tackle the problem from its roots, that is, addressing it as a basic feature of the "Lengua Castellana y literatura" curriculum in ESO and Bachillerato.

KEYWORDS: Fake news, post-truth, educational innovation, informative speech, social networks.

Recibido:16/09/2020

Aceptado: 23/10/2020

Correspondencia: Francisco José Sánchez García, Facultad de Filosofía y Letras, Universidad de Granada, Campus Universitario de Cartuja, 18071 Granada. Email: franjose@ ugr.es

\section{INTRODUCCIÓN}

Como sabemos, las noticias falsas han existido siempre, si bien las estrategias de desinformación de masas se han ido adaptando a los condicionantes sociohistóricos de cada momento. En la actualidad, se dice que vivimos en la "era de la posverdad", concepto característico de este siglo XXI en el que la abrumadora cantidad de noticias y medios de comunicación, lejos de contribuir a una buena información de los ciudadanos a través de la prensa física, digital o plataformas digitales en sus diferentes soportes, llega a desbordar nuestra capacidad de juicio crítico (Durandin, 1995). Por la misma razón, el fenómeno de los bulos, noticias falsas o fake news dispone ahora del caldo de cultivo perfecto para su difusión exponencial, pues tiene el poder de "viralizar" masivamente en cuestión de minutos. Esta saturación informativa o exceso de información, que Cornella (2004) Ilama "infoxicación", es especialmente preocupante si pensamos en los adolescentes, que todavía no disponen de herramientas para evaluar la fiabilidad de las fuentes de información. Por otra parte, vivimos en lo que Guy Debord (1999) ha bautizado como la "sociedad del espectáculo", lo cual se traduce, para el tema que nos ocupa, en dar preeminencia al atractivo de las informaciones por delante de la veracidad. No se trata únicamente de que los medios (incluso los más serios) enfoquen sus informaciones mediante un envoltorio sugestivo o estimulante, a veces cayendo en técnicas que conocemos como "clickbait", consistentes en generar un mayor tráfico de visitas a una cabecera digital a cualquier precio, aunque el coste suponga comprometer la propia credibilidad (Gómez de Ágreda, 2018; Arias Maldonado, 2019; Alonso González, 2019). Lo verdaderamente preocupante es que la ciudadanía en general, y en especial las nuevas generaciones, ya se ha acostumbrado a centrar su atención en las noticias más "espectaculares", en aquellas que nos desinforman, porque precisamente son las que casi siempre carecen de rigor. (Pareira Parrado, 2019; Parra Valero y Oliveira, 2018; Jiménez Rodríguez, 2020). 
Los jóvenes españoles pasan su vida frente a las pantallas, que no solo les sirven para entretenerse o interactuar con sus iguales, pues también a través de las ellas acceden al conocimiento (Sánchez García, 2020). Los nuevos entornos digitales han facilitado enormemente el aprendizaje de niños y adolescentes, pero también nos sitúan ante un desafío crucial. ¿Están preparados los jóvenes para discriminar lo verdadero de lo falso en Internet? ¿Contribuye el sistema educativo a formar adecuadamente en la interpretación de los mensajes engañosos que circulan por la red?

Según el informe Digital News Report (2018), elaborado por la agencia de noticias Reuters, WhatsApp está ganando terreno como canal de difusión de noticias, compitiendo con Facebook, hasta el punto de haber multiplicado por cuatro su potencial como transmisor de informaciones. No en vano, la aplicación de mensajería ya es el medio favorito para informarse de los jóvenes de edades comprendidas entre 18 y 24 años. El avance imparable de estas plataformas como medio exclusivo de información entre los menores hace necesario un replanteamiento de la enseñanza del papel de los medios y las técnicas de e-Learning en los estudios no universitarios. Por ello, este artículo está dedicado a describir y caracterizar los hábitos informativos de los adolescentes españoles, a fin de plantear la necesidad de incorporar la problemática de las fake news (persuasión, manipulación, engaño) al currículo de Lengua Castellana y literatura de ESO y Bachillerato.

\section{2. ¿Cómo se informan los Jóvenes españoles?}

Los integrantes de la conocida como "generación Z", que comprende a los jóvenes nacidos entre 1994 y 2010, son "nativos digitales" (Prensky, 2001) y, por ende, desde su infancia han tenido contacto con la realidad a través de cualquier dispositivo con conexión a Internet, de modo que bien podríamos denominarlos la "generación de la pantalla" (Otero, 2009: 65). En paralelo, el desarrollo y democratización de las TIC (Martínez Ezquerro, 2016) ha hecho posible una sobreabundancia de contenido informativo, al que se tiene acceso de manera inmediata. A diferencia de los llamados "inmigrantes digitales" (nacidos antes de 1994 que se han tenido que adaptar a la revolución digital), la nueva generación es consciente, desde las primeras etapas de aprendizaje, de que puede recuperar cualquier dato que le interese en cualquier momento (Díaz Noci et al., 1999); atrás quedaron los estudios memorísticos para retener nombres y fechas. ¿Qué sentido tiene, si podemos recuperar ese conocimiento en cuanto sea menester? El conocimiento ahora es ubicuo, y como está en todas partes, también circula en todas direcciones de acuerdo con unos parámetros otrora impensables.

En la llamada "modernidad líquida" de la que habla Bauman (2011), Internet es el eje central en torno al cual gravitan los medios de comunicación tradicionales. Cabe destacar en este punto los tres rasgos fundamentales que han puesto patas arriba las dinámicas de acceso a la información: hipertextualidad (el texto informativo se construye en red, de manera que los lectores puedan moverse de unos a otros, hasta el infinito), multimedialidad (incorporación al texto de otros códigos audiovisuales que complementan y hacen más atractiva la información) e interactividad (componente que permite al lector comentar las noticias y compartirlas con otras personas, conocidas o no). 
Ahondando un poco más, por su propia naturaleza hipertextual, la tecnología condiciona los hábitos de lectura, y ello es especialmente palpable en lo tocante a las noticias. A diferencia del diario en papel, que distribuye las informaciones en secciones, atendiendo a un criterio de mayor o menor urgencia, y de mayor a menor importancia, en un espacio físico limitado, las noticias en red permiten navegar a otros contenidos relacionados, ampliar información, y lo que es más importante, difundirse a través de plataformas, redes sociales o aplicaciones de mensajería como WhatsApp (Gómez Silva, 2019). Evidentemente, la red no es frecuentada con el único propósito de informarse. De acuerdo con Sánchez Navarro y Aranda (2011: 34), el entretenimiento y las relaciones sociales destacan entre los adolescentes como los usos específicos más frecuentes, si bien la "información sobre temas de interés" se revela como una de las prioritarias (un 59,2\% de los encuestados en el estudio de los autores respondieron afirmativamente a esta pregunta), aunque no parecen considerar "esos medios como una fuente de información de primera necesidad, sino como formas de entretenimiento tradicional" (Sánchez Navarro y Aranda, 2011: 35), al mismo nivel que escuchar música, ver televisión o distribuir sus propios contenidos.

Como señala Bernal Triviño (2008: 92) "Internet ha superado la misión de ser un simple medio de comunicación y se ha convertido en un nuevo espacio social (Echeverría, 1998) marcado por la comunicación virtual" por el cual "las personas que están separadas físicamente comparten creencias y prácticas". De hecho, uno de los rasgos característicos de los jóvenes actuales es su necesidad de compartir aqueIlo que les Ilama la atención o les interesa, y esto es aplicable a una fotografía, un "meme", un video de humor de Internet y, por supuesto, también una noticia. Por otra parte, se impone un ritmo diferente de lectura, mucho más veloz, menos detenido y, por tanto, menos reflexivo sobre aquello que se lee. Esto vale tanto como decir que los "nativos digitales" filtran los contenidos con una menor capacidad crítica y, de este modo, son mucho más vulnerables a cualquier tipo de manipulación.

Volviendo al estudio de Sánchez Navarro y Aranda (2011), fundamentado en la realización de una encuesta, los jóvenes españoles se guían por tres criterios acerca de la confiabilidad de la información obtenida en línea (en general, no solo en lo tocante a las noticias on line):

a) Sentido común (apariencia de veracidad).

b) Prestigio de la fuente (número de consultas o grado de conocimiento).

c) Reiteración (búsqueda de la misma información en diferentes medios).

De acuerdo con esto, cabría suponer que son plenamente conscientes del problema y en su mayoría están capacitados para escapar de la desinformación. Por eso conviene que ahondemos un poco más en la percepción de la información, del hecho noticioso en sí, y de las vías a través de las que los adolescentes reciben las noticias. Tal como recoge Ruiz Grau (2015) en su reciente estudio acerca de las fuentes de información de los niños y jóvenes españoles, los chicos y chicas de entre 12 y 15 años destacan el carácter reiterativo de los temas tratados, sobre todo en televisión, mientras que los mayores de 16 subrayan el concepto de negatividad en los sucesos informativos. Entre los soportes de acceso a la información, la autora señala que los jóvenes españoles 
escogen Internet para informarse porque "la Web ofrece noticias con las que pueden hacer cosas y las reciben sólo cuando las quieren para el 83\%" (Ruiz Grau, 2015: 590). Dicho de otro modo, en un escenario "multitarea" de "hiperconectividad" (Marín Casanova, 2019), que entendemos como consustancial y característico de la "generación $Z^{\prime \prime}$, Internet les ofrece la libertad y variedad promovidos por los nuevos y cambiantes hábitos de consumo, desde un dispositivo móvil, sin ataduras ni límites.

No debe extrañarnos que consideren la prensa tradicional en papel y los informativos de TV como medios demasiado serios y estáticos, propios de los adultos. El declive de la prensa tradicional en el sector juvenil viene explicándose desde la década del 2000 por motivos como la falta de tiempo, la preferencia por otros soportes y el poco interés en los contenidos, sumados a "la reducida relevancia de las noticias para su vida cotidiana y la escasa conexión con sus experiencias personales y sus intereses". (Casero-Ripollés, 2012: 152)

En cualquier caso, Ilama la atención la rapidísima adopción de Internet como vía preferente para informarse, toda vez que en la década anterior, la mayoría de los jóvenes aún ponían en duda su fiabilidad y veracidad, prefiriendo hacerlo por la televisión y la radio. (Sabés Turmo, 2005: 109) ¿A qué puede deberse este rapidísimo "relevo mediático"? Nos lo aclara Bernal Triviño:

¿Por qué prefieren Internet para informarse? Los propios jóvenes admiten que la rapidez, la actualización, la disponibilidad horaria continua, el diseño, el multimedia y la interactividad son los pilares sobre los que se asienta su éxito. En cambio, critican que los contenidos de la televisión son cada vez peores; y que la prensa papel no tiene capacidad de actualización, hay que comprarla, los textos de las noticias son muy largos y el diseño es poco atractivo (...) Internet se enfrenta al desafío de ser el foco de atracción informativa para los jóvenes. (2009: 126-127)

En la práctica, los medios están viendo como su poder se ve cada vez más mermado:

Durante años, Twitter ha fijado la agenda informativa, pero ahora los medios se enfrentan a una era post-Twitter, porque plataformas como WhatsApp o Telegram han permitido transformar mensajes inmediatos también en noticias, de forma que la audiencia pueda condicionar la agenda (Batra, 2016, citado en Palomo y Sedano, 2018: 1387).

Como señala Yuste (2015: 181-182), las razones tienen que ver con la preferencia por otros medios y soportes y la falta de interés por los contenidos que ofrecen los medios convencionales, que no reflejan las problemáticas juveniles.

\section{Los TEXTOS INFORMATIVOS EN EL CURRÍCULO DE LENGUA CASTELLANA Y LITERATURA}

Desde la implantación de la LOGSE (1990, con concreción de los contenidos del currículo en el Real Decreto 1007/1991 de 14 de junio), pasando por las sucesivas reformas educativas hasta la actual LOMCE (promulgada en 2013, que explicita los contenidos curriculares que deben desarrollarse en el Real Decreto 1105/2014 de 26 de diciembre), no ha habido cambios drásticos en el currículo de la asignatura "Lengua 
castellana y literatura", y menos aún en el tratamiento de la prensa y los medios de comunicación. El temario de la materia se ha visto mínimamente modificado en varias ocasiones, pero las diferencias no son sustanciales, manteniéndose intacto el andamiaje conceptual y las metodologías aplicables, tanto en Secundaria como en Bachillerato.

En este punto, queremos reflexionar sobre el papel de la prensa y los medios en los temarios de la asignatura, no solo como instrumento de trabajo sino especialmente como objeto de estudio. Tradicionalmente, las modalidades de trabajo con prensa en el aula suelen encajar en tres categorías (Feria, 1994, citado en Sánchez García, 2012: 101):

a) La prensa como objeto de conocimientos

- Análisis de noticias

- Fuentes de información

- Género y estilo

- ¿Cómo se hace un periódico?

- Estudio de la imagen

- Tecnología de la comunicación

- Línea informativa

b) La producción propia de la prensa

- Prensa mural (gráficos, informativos, monográfico, interdisciplinar, cartel, de humor, histórico o fantástico)

- Prensa escolar

- Banco de noticias

c) La prensa como material curricular

- Lectura en corro

- Seguimiento monográfico

- Proyectos de trabajo

- Hemeroteca y archivo

- Fichas de prensa

- Roles y simulaciones

- Investigación del medio con prensa

- Tópicos y centros de interés

Naturalmente, estas actividades, que ya se recogen entre las propuestas para Primaria, tienen su continuidad en Secundaria, cuestión a la que ya se refirieron Quiles Cabrera, Martínez Ezquerro y Palmer (2019), pero suelen quedar relegadas como "flecos" marginales con los que completar el tema de comunicación o tipos textuales, por ejemplo. 
Hasta Bachillerato, no se trabaja profundamente con los textos de prensa. Los textos periodísticos son muy utilizados en la asignatura, pero casi siempre como excusa para repasar contenidos gramaticales o trabajar la comprensión lectora. También, en el caso de los artículos de opinión, se repasa el estilo y los recursos retóricos (Martínez Ezquerro, 2018).

Hemos recopilado información actualizada de los manuales de los cuatro cursos de ESO y los dos cursos de Bachillerato de cuatro editoriales (Santillana, Algaida, Oxford y Anaya), a fin de clarificar qué contenidos se imparten. Podemos observar que los temas tocantes a los medios de comunicación abordan una serie de aspectos esenciales, que desglosamos en la tabla siguiente:

Tabla 1. Contenidos relacionados con los medios en los manuales seleccionados (Elaboración propia)

\begin{tabular}{|c|c|c|c|c|}
\hline & Santillana & Algaida & Oxford & Anaya \\
\hline $1^{\circ} \mathrm{ESO}$ & $\begin{array}{l}\text { - Clases de textos } \\
\text { - La noticia } \\
\text { - Lenguaje e inter- } \\
\text { net }\end{array}$ & - La noticia & - La noticia & - La noticia \\
\hline $2^{\circ} \mathrm{ESO}$ & $\begin{array}{l}\text { - Prensa digital } \\
\text { - Géneros informati- } \\
\text { vos (reportaje) } \\
\text { - Géneros de opi- } \\
\text { nión (editorial) }\end{array}$ & $\begin{array}{l}\text { - Textos de informa- } \\
\text { ción } \\
\text { - Textos de opinión }\end{array}$ & - El reportaje & $\begin{array}{l}\text { - Características del lengua- } \\
\text { je periodístico } \\
\text { - Textos periodísticos y } \\
\text { publicitarios } \\
\text { - Ejemplos de textos pe- } \\
\text { riodísticos (clasificación, } \\
\text { sección, estructura). }\end{array}$ \\
\hline $3^{\circ} \mathrm{ESO}$ & $\begin{array}{l}\text { - Los medios } \\
\text { - Reportaje } \\
\text { - Comentario de } \\
\text { texto }\end{array}$ & $\begin{array}{l}\text { - Los textos periodísti- } \\
\text { cos } \\
\text { - Textos argumentati- } \\
\text { vos }\end{array}$ & $\begin{array}{l}\text { - Textos en red } \\
\text { - La crónica } \\
\text { - El reportaje }\end{array}$ & $\begin{array}{l}\text { - Escribir es... } \\
\text { - Taller de comprensión } \\
\text { oral }\end{array}$ \\
\hline $4^{\circ} \mathrm{ESO}$ & $\begin{array}{l}\text { - Los medios } \\
\text { - Géneros periodís- } \\
\text { ticos } \\
\end{array}$ & $\begin{array}{l}\text { - Definición de texto } \\
\text { - Niveles de lengua }\end{array}$ & $\begin{array}{l}\text { - Informativos } \\
\text { - Documentales } \\
\text { - Reportajes } \\
\end{array}$ & $\begin{array}{l}\text { - La prensa } \\
\text { - Comprensión lectora }\end{array}$ \\
\hline $1^{\circ}$ Bachillerato & $\begin{array}{l}\text { - Modalidades } \\
\text { textuales } \\
\text { - Géneros de opi- } \\
\text { nión } \\
\text { - Análisis de un } \\
\text { texto } \\
\end{array}$ & $\begin{array}{l}\text { - Textos periodísticos y } \\
\text { publicitarios } \\
\text { - Columnas periodísti- } \\
\text { cas } \\
\text { - Comentario de texto }\end{array}$ & $\begin{array}{l}\text { - El comentario } \\
\text { de textos no } \\
\text { literarios } \\
\text { - Textos orales y } \\
\text { textos escritos }\end{array}$ & $\begin{array}{l}\text { - Textos periodísticos y } \\
\text { publicitarios }\end{array}$ \\
\hline $2^{\circ}$ Bachillerato & $\begin{array}{l}\text { - El texto perio- } \\
\text { dístico y el texto } \\
\text { publicitario } \\
\text { - Comentarios de } \\
\text { texto }\end{array}$ & $\begin{array}{l}\text { - Información, persua- } \\
\text { sión y argumenta- } \\
\text { ción. } \\
\text { - Géneros periodísticos } \\
\text { - Comentario de textos }\end{array}$ & $\begin{array}{l}\text { - Géneros infor- } \\
\text { mativos } \\
\text { - Comentario de } \\
\text { textos periodís- } \\
\text { ticos }\end{array}$ & $\begin{array}{l}\text { - Características } \\
\text { - Funciones de los medios } \\
\text { - Elementos comunicación } \\
\text { - Textos periodísticos orales } \\
\text { - Céneros informativos } \\
\text { - Géneros de opinión } \\
\text { - Comentario de textos }\end{array}$ \\
\hline
\end{tabular}


Hay que aclarar que hemos recogido los títulos concretos de los epígrafes y también los contenidos en los que se aprovechan materiales de prensa escrita, digital o medios audiovisuales como soporte, aunque sea de forma colateral. Como queda de manifiesto, la visión predominante recogida en todos los manuales es la acostumbrada: el estudio de los medios de comunicación impresos (en algún caso se mencionan los diarios digitales), incidiendo en los géneros periodísticos (informativos/ de opinión) e incorporando comentarios de textos: noticia, reportaje, editorial, crónica. No hallamos ni una sola mención a las noticias falsas, o a la fiabilidad o veracidad de las informaciones divulgadas a través de Internet.

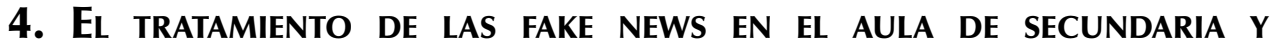 bachillerato. Propuestas de implementación didáctica}

No cabe duda de que la incorporación de metodologías que tengan en cuenta la prensa como objeto de estudio y no como mero pretexto hace necesaria la implementación de propuestas didácticas específicas, centradas en la descripción, identificación y crítica de las noticias falsas como fenómeno en boga de nuestro tiempo. Se trata, en última instancia, de alcanzar la tan ansiada "alfabetización digital" (McDougall, Brites, Couto y Lucas, 2019) o "mediática" (Fernández García, 2017), con la que dotar a los jóvenes estudiantes de los rudimentos necesarios para moverse con garantías en el entorno virtual. Precisamente, uno de los grandes retos de la educación pasa por adaptarse a las nuevas circunstancias sociales, lo cual va mucho más allá que la mera adopción de las TIC en clase. No en vano, como señala Zygmunt Bauman:

En el pasado, la educación adquiría muchas formas y demostró ser capaz de ajustarse a las cambiantes circunstancias, fijándose nuevos objetivos y diseñando nuevas estrategias.

Pero, lo repito, el cambio actual no es como los cambios del pasado. En ningún otro punto de inflexión de la historia humana los educadores debieron afrontar un desafío estrictamente comparable con el que nos presenta la divisoria de aguas contemporánea. Sencillamente nunca antes estuvimos en una situación semejante. Aún debemos aprender el arte de vivir en un mundo sobresaturado de información. Y también debemos aprender el aún más difícil arte de preparar a las nuevas generaciones para vivir en semejante mundo. (Bauman, 2008: 46)

Para empezar, coincidimos con la dificultad que supone para muchos docentes aplicar nuevas metodologías centradas en el e-learning, dada la enorme brecha entre la "cultura de los nativos digitales" y la que enseñan sus profesores, ya que:

Los docentes saben menos de la tecnología que sus estudiantes y, en consecuencia, los nativos digitales pueden estar siendo formados en un modo que no es relevantes para ellos. (...) Es difícil mantenerlos atentos en una clase tradicional de exposición de contenidos por parte del profesor, porque tienen la percepción de que ese contenido lo pueden consultar en Internet, lo pueden intercambiar entre ellos, localizar otras fuentes, elaborar mapas o visualizaciones. En definitiva, tienden a participar activamente en 
la construcción de su propio conocimiento. Ante esta situación, o bien los inmigrantes digitales aprenden a enseñar de una manera diferente y más atractiva, o bien los nativos digitales "retroceden" adaptando sus capacidades intelectuales a su entorno de aprendizaje. (García, Portillo, Romo y Benito, 2007: 4)

¿Qué clase de herramientas didácticas debemos utilizar? Como bien señala Prensky (2013), esta nueva generación de adolescentes, los "nativos digitales":

a) No quieren charlas teóricas

b) Quieren que se tenga en cuenta su opinión

c) Quieren desarrollar en el aula sus aficiones e intereses

d) Quieren ser creativos utilizando las herramientas digitales

e) Quieren ser parte activa de su proceso de aprendizaje

f) Quieren una educación conectada con la realidad, con su realidad

Siendo esto así, parece claro que los materiales didácticos desplegados en clase habrán de resultar atractivos y participar de esta pedagogía de la "co-asociación" (aprendizaje centrado en el alumno) que defiende Prensky. Dicho de otro modo, no se trata de imponer contenidos, sino de proponer temas interesantes, propiciar que los discentes se hagan preguntas relevantes y traten de resolverlas de manera cooperativa y participativa, con los docentes como guías y/o intermediarios de su proceso de aprendizaje.

Para Prensky (2013), el papel de la tecnología en el aula es crucial para alcanzar los objetivos pedagógicos propuestos. El desempeño profesional del docente no ha de centrarse en la explicación del manejo de las TIC (que el estudiantado ya conoce de sobra), sino que deberá promover la autosuficiencia y compromiso con los temas abordados.

Por todo lo expuesto en los anteriores epígrafes, el tratamiento de la manipulación informativa en el currículo de Secundaria y Bachillerato debería ser una prioridad, a pesar de su escasa (o directamente nula) presencia en los manuales estudiados. Antes apuntábamos que empieza a incorporarse a los temarios la enseñanza de los rasgos característicos de la prensa digital, pero es no es suficiente. No basta con describir las "estructuras" y los géneros periodísticos (que también); conviene ir más allá de la simple distinción entre géneros informativos y de opinión para hacer que los estudiantes sean conscientes de la importancia de reconocer las estrategias de manipulación de los medios tradicionales, y muy especialmente, de la veracidad o falsedad de ciertas informaciones que circulan libremente por la red y que la mayoría pueden llegar a dar por ciertas cuando se trata de bulos que carecen por completo de credibilidad. Aparte de los géneros periodísticos, deben tener cabida en el temario conceptos como "manipulación", "tergiversación", "línea editorial", "bulo"/"fake news", "falacia", "persuasión" y "gancho informativo", entre otros.

Como hemos visto, el uso de aplicaciones de mensajería como WhatsApp está ampliamente extendido entre los adolescentes (Palomo y Sedano, 2018), de 
modo que puede ser una buena herramienta para introducir la cuestión, especialmente a partir del segundo ciclo de la Educación Secundaria Obligatoria. Por ejemplo, los docentes pueden comenzar a abordarlo con una práctica estimulante: el envío de varios mensajes a través de WhatsApp a los estudiantes, con enlaces a noticias de fuentes solventes, y otras algo más cuestionables, como la siguiente:

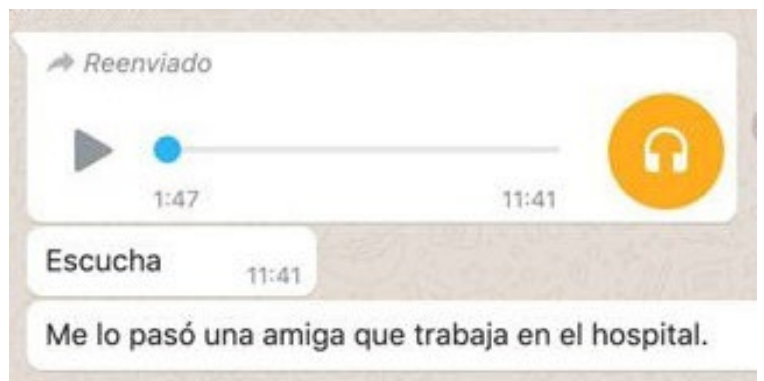

Figura 1. Captura de pantalla de WhatsApp. Audios de "testimonios reales"

Este tipo de audios de supuestos testimonios "reales" son muy habituales en situaciones de tensión informativa (por ejemplo, la crisis del COVID-19). Palomo y Sedano (2018: 1390) recogen ejemplos típicos de fake news difundidas a través de Whatsapp (furgoneta blanca que secuestra niños en Málaga, página web que ofrece suscripción gratuita a Netflix, actualización de Windows que esconde un virus o aguja infectada con VIH en manguera de una gasolinera, entre otros). A continuación, se iniciaría un debate con el grupo para reflexionar sobre cuáles son los rasgos o atributos presentes en este tipo de mensajes que les llaman la atención y hasta qué punto difundirían una información de este tipo.

Esta misma red de mensajería puede servir como trampolín para que los estudiantes jueguen a elaborar sus propias noticias falsas con un enfoque humorístico, emulando la propuesta del diario satírico El Mundo Today:

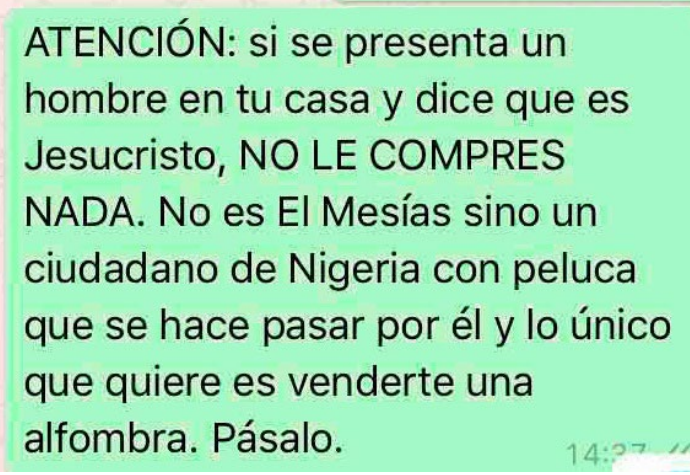

Figura 2. Whatsapp humorístico. Fuente: El Mundo Today (15/09/2017) 
También podemos servirnos de contenido de Twitter para Ilamar la atención sobre la difusión de bulos con una clara intención de tergiversación política.
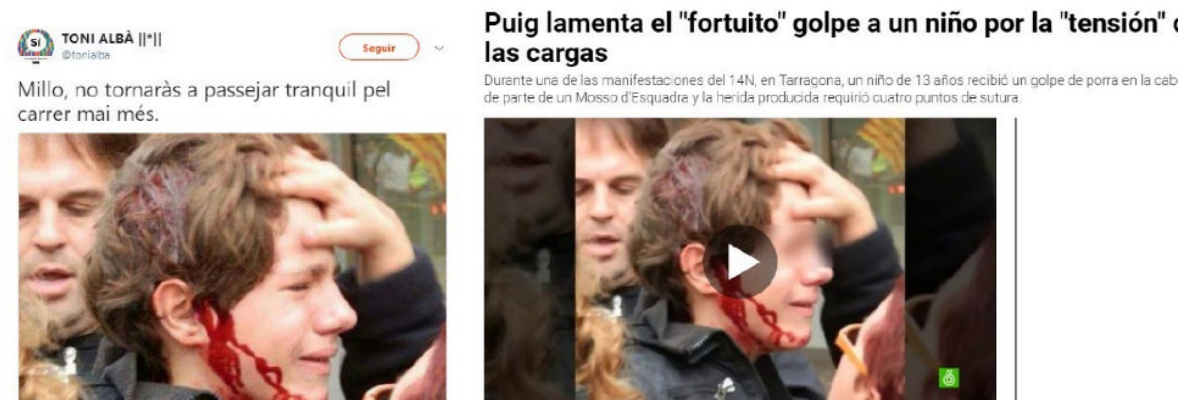

Figura 3. Comparativa de tweets durante la jornada participativa del 1-O de 2017 en Cataluña

Por último, se pasaría un cuestionario para poner en común las impresiones acerca de estos contenidos y su viralización. Se trata de discutir cuestiones como las siguientes:

- ¿Qué tipo de mensajes con contenido informativo difundimos a través de redes?

- ¿Detectamos intencionalidad política?

- ¿Qué opinamos acerca de su fiabilidad?

- ¿Proceden de fuentes oficiales?

- ¿Hemos contrastado esa información revisando diarios o fuentes solventes?

- Después de lo visto en clase, ¿qué entendemos ahora por noticia falsa? ¿Qué es para nosotros un bulo?

La práctica de la detección y monitorización de noticias falsas o bulos en el aula puede completarse si se anima a los estudiantes a consultar las diferentes plataformas de "verificación" (fact-checking) que han surgido en los últimos años en nuestro país, como Newtral, Maldito Bulo o Con B de Bulo, entre otros. Se podría plantear la creación en el aula de una plataforma por un grupo de la clase que emule a las reales y trate de desmontar noticias disparatadas escritas por otro grupo de estudiantes. Es fundamental estimular a los propios estudiantes para que sean ellos mismos quienes, una vez propuesto el tema, incorporen sus experiencias con bulos y noticias virales al debate del aula.

\section{Conclusiones}

En un contexto de posverdad y "hechos alternativos", en el que disponemos de mucha más información de la que estamos capacitados para procesar, y que encontramos en la palma de la mano a través de un teléfono móvil, hemos perdido gran 
parte de nuestra capacidad de discernimiento acerca de la calidad y rigor de las noticias. Si los adolescentes, en tanto que "nativos digitales", no son capaces de discernir entre las fake news y las noticias rigurosas de fuentes contrastadas, parece claro que hemos de poner el foco en la educación. Aunque el currículo de Lengua Castellana y literatura de ESO y Bachillerato recoge los materiales periodísticos, hemos podido comprobar que casi siempre sirven únicamente como soporte textual para explicar contenidos gramaticales o discursivos, sin hacer hincapié en la problemática de la "infoxicación".

Creemos haber podido reflejar en este trabajo el radical y vertiginoso cambio en los hábitos de consumo informativo por parte de las nuevas generaciones en los últimos años. Investigaciones como las anteriormente expuestas evidencian el creciente $-y$ cada vez más abrumador- acceso de los jóvenes a plataformas, redes sociales y de mensajería como fuente primaria de información, y por ende, el abandono de los diarios impresos y digitales convencionales o los informativos de radio y TV. Prevalece la difusión cruzada a través de WhatsApp, Twitter o Facebook de informaciones de consumo rápido y fácil acceso, altamente polarizadas a nivel ideológico, procedentes de fuentes no contrastadas (o directamente falsas o engañosas), elaboradas en su mayoría a partir de hechos o sucesos de gran impacto, escasa fiabilidad y claro interés por generar un alto tráfico de visitas a los medios en cuestión, casi siempre recurriendo a titulares tendenciosos, en la órbita de la tan frecuente moda del "clickbait".

La importancia del problema hace necesaria una revisión del currículo escolar para incorporar este contenido en el aula de manera transversal, fomentando la conciencia crítica del estudiantado en la recepción e interpretación de noticias. En una sociedad que cambia a un ritmo tan acelerado, es imprescindible aprovechar el potencial que nos brindan los medios sociales y su tratamiento de la actualidad como plataforma para generar debate en el aula y llamar la atención de los estudiantes sobre conceptos clave como verdad y falacia, tergiversación, interés ideológico, gancho informativo, persuasión, entre otros que orbitan en torno a la posverdad de nuestro tiempo. No se trata de "criminalizar" la ventaja indudable que representan las nuevas tecnologías, sino más bien aprovechar su potencial para aprender a leer las noticias a través de las pantallas desechando las informaciones "virales" poco rigurosas y valorando las fiables y documentadas.

En suma, urge atender a la imprescindible "alfabetización digital" de los estudiantes, especialmente a partir de Educación Secundaria Obligatoria y Bachillerato, mediante un enfoque holístico e integrador que resulte motivador para los jóvenes y les proporcione herramientas para defenderse de la "infoxicación" a la que sin duda estarán expuestos a lo largo de su vida.

\section{REFERENCIAS BIBLIOGRÁFICAS}

Alonso González, M. (2019). Fake news: desinformación en la era de la sociedad de la información. Ámbitos: Revista Internacional de Comunicación, 45, 29-52. https://doi.org/10.12795/Ambitos.2019.i45.03 
Arias Maldonado, M. (2019). Understanding Fake News: Technology, Affects, and the Politics of the Untruth. Historia y comunicación social, 24(2), 533-546. https://doi. org/10.5209/hics.66298

Bauman, Z. (2008). Los retos de la educación en la modernidad líquida. Barcelona: Gedisa.

Bernal Triviño, A. (2010). Medios de comunicación, jóvenes y diseño de la información. Comunicación y desarrollo en la era digital. Actas del Congreso AE-IC (p. 154). Málaga: Universidad de Málaga.

Bernal Triviño, A. (2009). Jóvenes, noticias e internet. El factor del diseño. Vivat Academia, 109, 124-128. http://doi.org/10.15178/va.2009.109.124-128

Bernal Triviño, A. (2008). Preferencias del diseño de la información periodística en internet por parte de los jóvenes. Tesis doctoral. Málaga: Universidad de Málaga.

Casero Ripollés, A. (2012). Más allá de los diarios: el consumo de noticias de los jóvenes en la era digital. Comunicar, 39(20), 151-158.

Cornella, A. (2004). Infoxicación: buscando un orden en la información. Barcelona: Infonomía.

Díaz Noci, J. y Meso Ayerdi, K. (1999). Periodismo en Internet. Modelos de la prensa digital. Bilbao: Universidad del País Vasco.

Debord, G. (1999). La sociedad del espectáculo. Valencia: Pre-textos.

Durandin, G. (1995). La información, la desinformación y la realidad. Barcelona: Paidós.

Fenton, N. y Freedman, D. (2018). Fake democracy, bad news. Comunicação \& Educação, 23(1), 107-126. Recuperado de http://research.gold.ac.uk/22330/1/Fenton-Fake_democracy.pdf

Fernández García, N. (2017). Fake news: una oportunidad para la alfabetización mediática. Nueva sociedad, 269, 66-77.

García, F., Portillo, J., Romo, J. y Benito, M. (2007). Nativos digitales y modelos de aprendizaje. Comunicación presentada en SPDECE. IV Simposio Pluridisciplinar sobre Diseño, Evaluación y Desarrollo de Contenidos Educativos Reutilizables. Bilbao. Recuperado de http://ceur-ws.org/Vol-318/Garcia.pdf

Gómez de Agreda, A. (2018). Posverdad y 'fake news'. Falsas noticias, no noticias falsas. Telos: Cuadernos de comunicación e innovación, 109, 18-21.

Gómez Silva, M. (2019). Whatsapp, un agujero negro de fake news. Inversión: el semanario líder de bolsa y gestión de patrimonios, 1134, 22-23.

Jiménez Rodríguez, A. (2018). Fake News: La verdad de las noticias falsas. Barcelona: Plataforma.

Ley Orgánica 1/1990 de 3 de Octubre, de Ordenación General del Sistema Educativo (LOGSE). Boletín Oficial del Estado, 238, 4 de Octubre de 1990, 28927-28942. 
Ley Orgánica 8/2013 de 9 de Diciembre, para la Mejora de la Calidad Educativa (LOMCE). Boletín Oficial del Estado, 295, 10 de Diciembre de 2013, 9785897921.

Marín Casanova, J. A. (2019). Posverdad y fake news. ¿Moda o modo? Ámbitos: revista de estudios de ciencias sociales y humanidades, 41, 105-111. https://hdl. handle.net/11441/90221.

Martínez Ezquerro, A. (2018). Entre el ejercicio literario y periodístico. Aplicaciones retóricas en la prensa actual. Tonos digital. Revista de estudios filológicos, 34.

Martínez Ezquerro, A. (2016). Las TIC en lengua castellana y literatura. Criterios de calidad y recursos didácticos. Revista DIM: Didáctica, Innovación y Multimedia, 34 .

Martínez Gras, R. (2014). Desde internet a las redes sociales: acceso y uso de las tecnologías de la información y la comunicación en los jóvenes universitarios. En $\mathrm{H}$. Cairo y L. Finkel (Coords.), Crisis y Cambio. Propuestas de la Sociología. Volumen 3 (pp. 828-832). Madrid: Universidad Complutense de Madrid.

McDougall, J., Brites. M. J., Couto, M. J. y Lucas, C. (2019). Alfabetización digital, fake news y educación. Culture and Education. Cultura y Educación, 31(2), 209212.

Otero, H. (2009). Nativos digitales: los jóvenes y las tecnologías de la información y de la comunicación. Crítica, 962, 64-69.

Palomo Torres, M. B. y Sedano Amundarain, J. A. (2018). WhatsApp como herramienta de verificación de fake news. El caso de B de Bulo. Revista Latina de Comunicación Social, 73(13), 1384-1397. http://doi.org/10.4185/RLCS-2018-1312

Parra Valero, P. y Oliveira, L. (2018). Fake news: una revisión sistemática de la literatura. Observatorio $\left(O B S^{*}\right), 12$ (Extra 1), 54-78. https://doi.org/10.15847/obsOBS12520181374

Parreira Parrado, M. (2019). La proliferación de las fake news y sus algoritmos daña la cultura democrática. Ámbitos: Revista internacional de comunicación, 45, 89-106.

Prensky, M. (2001). Digital natives, digital immigrants. On the Horizon, 9(5), 1-6. Recuperado de http://www.marcprensky.com/writing/Prensky\%20-\%20Digital\%20 Natives,\%20Digital\%20lmmigrants\%20-\%20Part1.pdf

Prensky, M. (2013). Enseñar a nativos digitales. Madrid: SM.

Quiles Cabrera, M. C., Martínez Ezquerro, A. y Palmer, I. (2019). Enredos de palabras. Gramática y uso de la lengua en nuevos espacios de comunicación. Barcelona: Graó.

Real Decreto 1007/1991, de 14 de junio, por el que se establecen los objetivos correspondientes a la etapa de Educación Secundaria y a las distintas áreas que en la misma se han de impartir, así como los contenidos y los criterios de evaluación 
correspondientes a cada una de ellas, junto con el horario escolar mínimo que debe dedicarse al desarrollo de dichos contenidos. Boletín Oficial del Estado, 152, 26 de junio de 1991, pp. 21193-21195.

Real Decreto 1105/2014, de 26 de diciembre, por el que se establece el currículo básico de la Educación Secundaria Obligatoria y del Bachillerato. Boletín Oficial del Estado, 3, 3 de enero de 2015, pp. 169-546.

Reuters Institute/University of Oxford (2018). Digital News Report. Recuperado de http://www.digitalnewsreport.org/survey/2018/the-rise-of-messaging-apps-fornews/.

Ruiz Grau, S. (2015). Las redes sociales en internet como fuente de información para los jóvenes frente a los medios convencionales. En S. Cortiñas, A. Elduque, F. Alonso y M. Darriba (Coords.), Periodismo actual y futuro: investigación, docencia e innovación (pp. 585-599). Barcelona: Universitat Pompeu Fabra/Sociedad Española de Periodística.

Sabés Turmo, F. (2005). Jóvenes y medios: ¿encuentro o desencuentro? Cuadernos de periodistas, 5, 101-109.

Sánchez García, R. (2020). Entre el canon literario poético y las redes sociales. Algunas respuestas para nuevos lectores en la era digital. En I. Aznar Díaz, M. P. Cáceres Reche, J. M. Romero Rodríguez y J. A. Marín Marín (Eds.), Investigación e innovación educativa. Tendencias y retos (pp. 123-136). Madrid: Dikynson.

Sánchez García, R. (2012). La prensa en la sociedad del conocimiento. A propósito del uso del periódico en el aula de primaria. En R. Sánchez, P. Isla y F. J. Sánchez (Coords.), Medios de comunicación en el aula: enfoques y perspectivas de trabajo (pp. 95-102). Barcelona: Octaedro.

Sánchez Navarro, J. y Aranda, D. (2011). Internet como fuente de información para la vida cotidiana de los jóvenes españoles. El profesional de la información, 20(1), 32-37.

Yuste, B. (2015). Las nuevas formas de consumir información de los jóvenes. Revista de Estudios de Juventud, 108, 179-191. 